\title{
Estimating Spray Characteristics of the Air-Blast atomizer of a Typical Jet Engine using Definition of the New Non-dimensional Number K: Numerical and Experimental Study
}

\author{
Mohammad Mehdi DOUSTDAR, Kiumars KHANI AMINJAN*, Houman ALIPOUR, Maryam ALIAKBARI
}

\begin{abstract}
In this paper, by using a numerical solution and experiment investigation, a non-dimensional number is introduced to estimate the characteristics of a real engine airblast atomizer spray. This type of atomizers is usually used in airplain engines. The test is conducted in ambient atmospheric pressure and at $300 \mathrm{~K}$ temperature and the effects of pressure on atomizer flow rate and spray con angle are investigated. We used the discrete phase model and real information of the ALF502 engine for simulations and for boundary conditions respectively. Since the main application of this airblast atomizer is in aircraft engines and in the real working conditions, none of the pressure and flow rate parameters is constant, thus, the main aim of this research is to define a nondimensional number $K$, which considers the effects of working liquid flow rate, air flow rate and pressure on the droplets average diameter and spray con angle simultaneously. The results showed that, in general, with the increase of non-dimensional $K$ number, the average diameter of droplets in primary and secondary break up increases, but spray con angle decreases. Furthermore, numerical solution results are compared with experiment results and $9.98 \%$ error was observed.
\end{abstract}

Keywords: airblast atomizer; droplet average diameter; non-dimensional number $K$; spray cone angle

\section{INTRODUCTION}

Proper and homogeneous atomization of fuel and oxidant through atomizer will result in a stable and effective combustion in a combustion chamber. Thus, improving combustion chamber and injector performance will result in decrease of fuel consumption and air pollution. This will also produce a proper thrust force. The quality of atomizer operation has an important role in achieving a stable combustion. It should also have a uniform distribution in spraying the liquid. Atomizers with these characteristics are two liquid ones. The atomizers that mix fuel and oxidizer produce highly efficient and stable combustion, [1]. The necessity of homogenous spraying and proper atomization has made the study of these atomizers so important, thus extensive research has been done in this field. Rizkalla and Lefebvre, in a practical study investigated the air and liquid properties effects on liquid atomization in air blast atomizers [2]. Zheng et al. have studied air blast spray structures in the high pressure conditions. They used imaging techniques for deriving spray patterns [3]. Fan et al. worked on new types of air blast atomizers and their spraying characteristics. The results showed that type A atomizer with maximum 25 micrometer drop diameter is the best type for adjustable chamber [4]. Levy et al. worked on an air blast simplex atomizer which supplies air to the fuel spray through radial channels to disperse liquid film. Their study showed that droplet size reduced significantly when the air velocity grew up to $60 \mathrm{~m} / \mathrm{s}$ but further increment in air velocity had almost no effect on the droplet size [5].

Koch et al. investigated the performance of Prefilming Airblast Atomizers in unstable flow conditions. They used several LDV (Laser Doppler Velocimetry) and PTV (Particle Tracking Velocimetry) optical detectors [6]. Zhang et al. studied the numerical simulation of fuel-oil spray airbags. They simulated the airblast atomizer spray by using Fluent [7]. Batarseh et al. studied the fluctuations of the spray produced by the airblast atomizer. Their study examined the aerodynamic instability of the spray produced by an airblast atomizer [8]. Grech et al. investigated the effect of combustion chamber geometry on the performance of the airblast atomizer under atmospheric conditions. In their study, they used the CFD method for simulation [9]. Gepperth et al. studied primary droplet characteristics in the near field of a prefilming airblast atomizer by using three geometrical variants of a planar atomizer over a wide range of operating conditions. Their study showed that the droplet sizes are generally predicted too small [10]. Chong et al. studied the effects of air/fuel mass ratio on the spray properties of an internally mixed airblast atomizer [11]. Chaussonnet et al. developed a new cognitive model to predict droplet size distribution in largeeddy simulation of airblast atomizers [12]. Shafaee and Mahmoudzadeh numerically investigated the spray properties of an airblast atomizer with a dynamic mesh. They used OpenFOAM software to evaluate the effects of geometrical parameters and flow conditions on spray properties [13]. Roudini et al. have experimentally studied the pre-filming airblast atomizer spray properties. The purpose of their study was to examine and describe the influence of the nozzle geometry and a wide range of flow conditions on the spray performance of prefilming air-blast atomizers. An algorithm has been developed to analyze liquid ligaments and particles characteristics, close to the nozzle exit during various operational conditions. The results showed that the liquid conical core region, ligament formation and breakup length are significantly dependent on liquid flow rate and air pressure near the nozzle exit [14]. Kiumers et al. studied the pressure swirl atomizer using experimental and numerical methods to investigate the effects of pressure and geometrical parameters on spray properties $[15,16]$. Jamali et al. studied the formation of air cavities and the worthington jet due to the falling sphere into an oil film formed on water using a high-speed camera. They observed that when a very thin layer of silicon oil was placed on the surface of the water, a large air cavity and a worthington jet were observed [17]. Zhou et al. made an experimental investigation about the influence of airflow on droplet sizes. Their study showed that when there is no airflow, in the zone of diffusion angle of atomization field, on the connection line between the centre of nozzle's orifice and any point in the effective jetting range, the closer to the nozzle the droplet is, the smaller its size will 
be, and vice versa [18]. Mrzljak et al. studied DI diesel engines by quasi-dimesional method. Their study presented two components of developed quasi-dimensional numerical model: spray package penetration and gas inflow from the zone without combustion into the spray packages [19]. Seyedin et al. studied pressure swirl nozzle. Their study showed that by increasing the distance of the droplets from the centre of the spray cone, the velocity of the output drops decreases due to the friction effect near the wall of the nozzle's orifice [20].

The atomizer investigated in the present study has two primary and secondary ducts for fuel and also used air flow for better fuel atomization. The diameter of the primary duct is much smaller than that of secondary duct. The secondary duct is used at high-speed when the engine requires more fuel. Here, we studied the primary duct and the related airflow. The main application of this type of atomizer is in aircraft engines. In engine operation during flight, the pressure and exhaust parameters are not constant. Therefore, we introduced and studied a dimensionless number which includes the effects of the fuel flow to air flow ratio, and also the atmospheric pressure to the spray medium pressure ratio on the droplets diameter at the primary and secondary breakup and also on the spray cone angle. For this purpose, actual information of the ALF502 engine operation conditions was used [21]. The method of investigation is numerical and is validated with laboratory results.

\section{EXPERIMENTAL TEST}

The experiment was performed at ambient atmospheric pressure of $101325 \mathrm{~Pa}$ and temperature of $300 \mathrm{~K}$. In the test, water and also MIL7024 were used as working fluids, and the flow rate and spray cone angle at different upstream pressures were investigated. The atomizer, applied in the ALF502 engines, shown in Fig. 1, was designed in accordance with the high pressure combustion chamber pressure.

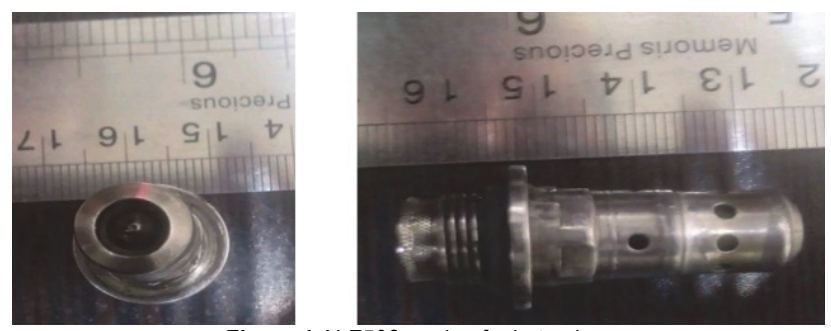

Figure 1 ALF502 engine fuel atomizer

During the test the injector was mounted on the injector plate and the injection control was done by upstream pressure adjustment and the amount of the control valve opening. To measure the mass flow rate a stopwatch and a graduated container were used. By dividing the volume of liquid collected over time, a volumetric flow rate can be obtained. To calculate the mass flow rate, it is necessary to pay attention to the density of the liquid. (Each cc of water is equal to 1 gram and each cc of MIL 7024 is equal to 0.767 gram). At the beginning of the test, a sudden opening of the valve may have a negative effect on the test result and reduces the accuracy of the test results, so we let the test time for each case be long enough to reach a completely stable condition. To make the test results more accurate, we repeated the test twice at each pressure and used the average of their results for our study. Usually the test results for the first and second time were very slightly different, which showed that these results are reliable. The angle of spray was measured by photoghraphy. Fig. 2 displays the injection process and the results of the test are indicated in Tab. 1.

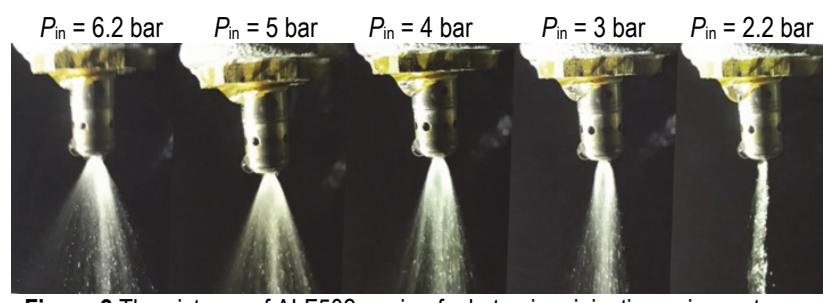

Figure 2 The pictures of ALF502 engine fuel atomizer injection using water as workinf fluid

Table 1 Atomizer test results with water

\begin{tabular}{|c|c|c|c|c|}
\hline$p_{\text {in }} /$ bar & $t / \mathrm{s}$ & $V / \mathrm{cc}$ & $\dot{m} / \mathrm{gr} / \mathrm{s}$ & Spray cone angle / deg \\
\hline 2.2 & 15.19 & 40 & 2.63 & 13.73 \\
\hline 3 & 12.05 & 38 & 3.15 & 28.65 \\
\hline 4 & 14.67 & 54 & 3.68 & 40.01 \\
\hline 5 & 12.45 & 52 & 4.17 & 49.17 \\
\hline 6.2 & 14.93 & 68 & 4.55 & 53.85 \\
\hline
\end{tabular}

The flow diagram and angle of the injection cone with respect to the back pressure of the atomizer are shown in Fig. 3.
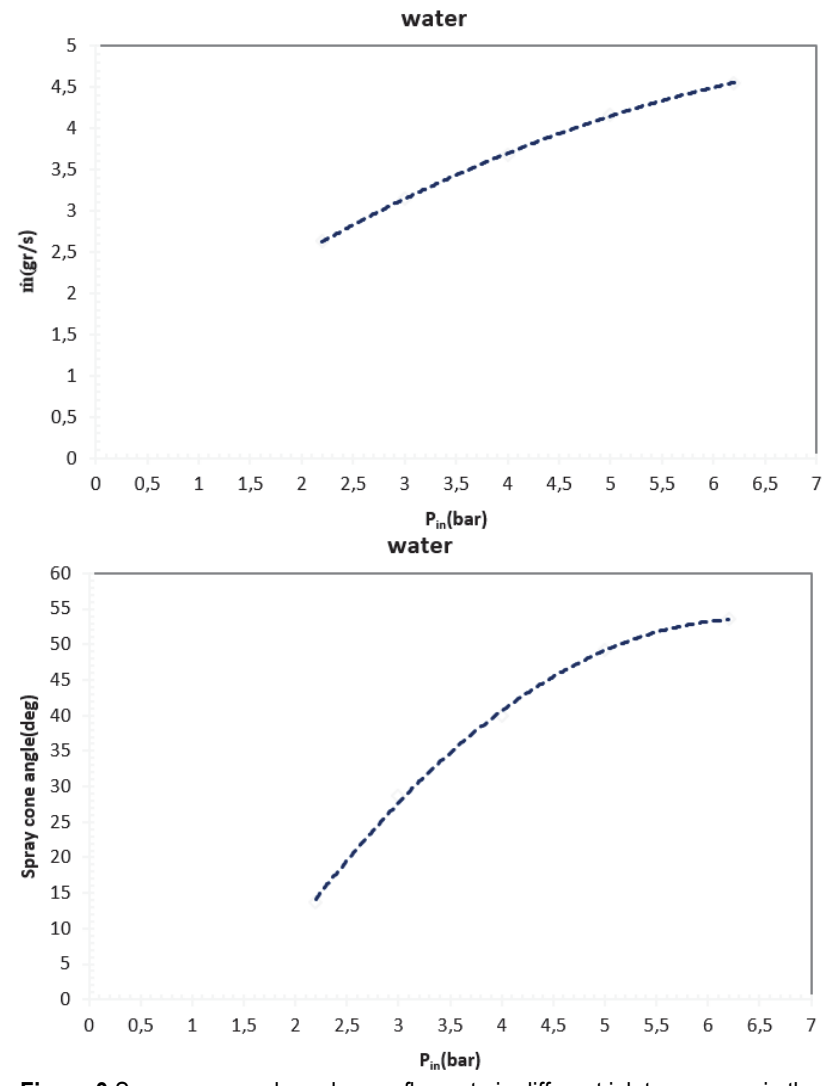

Figure 3 Spray cone angle and mass flow rate in different inlet pressures in the test with water

The experiment was repeated with MIL7024 fuel and the results are shown in Fig. 4. 

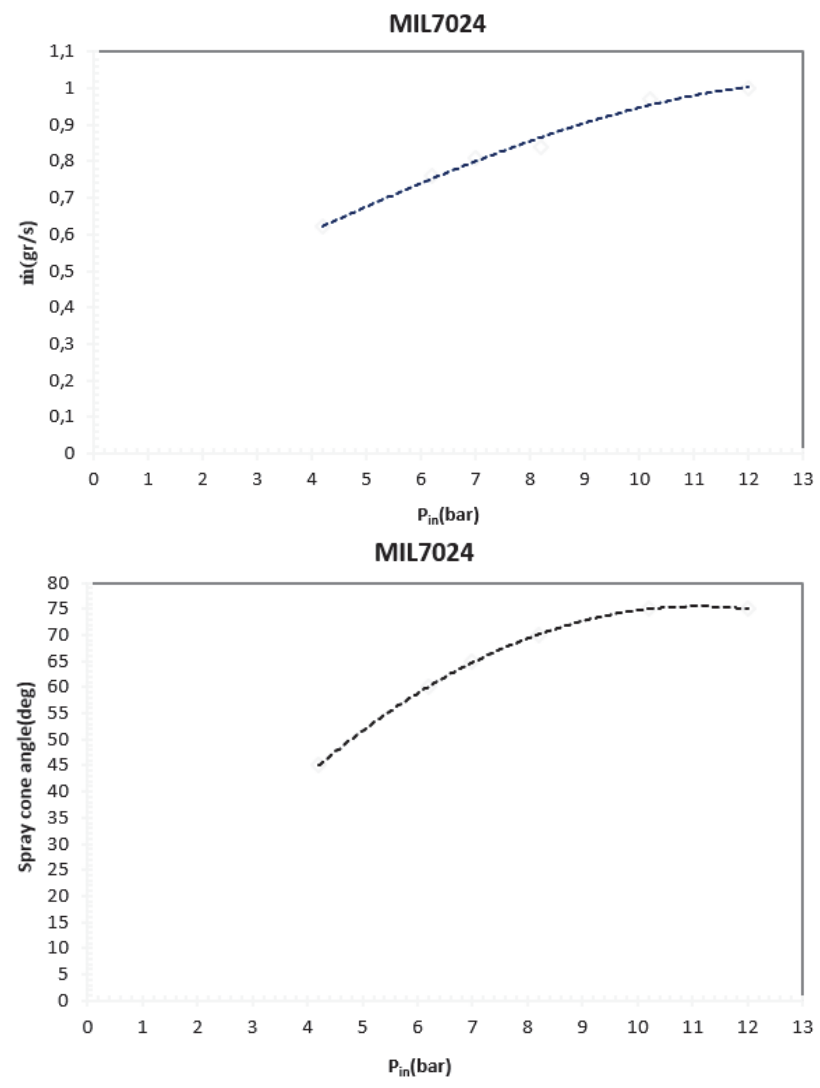

Figure 4 Spray cone angle and mass flow rate in different inlet pressures in the test with MIL7024

\subsection{Test Results}

Figs. 2 to 4 and Tab. 1 show the following results:

- By increasing the pressure, the spray cone angle increases. This increment is initially with a high slope and then a mild slope.

- $\quad$ By increasing the pressure, the flow rate increases with almost constant slope.

- The spray form is conical hollow form.

- By comparing the results of atomizer test with water and MIL7024 at the same pressures, it is observed that the mass flow rate with water is much higher than that of MIL. That is because of lower viscosity and higher density of water with respect to MIL.

- $\quad$ The difference between spray cone angle for MIL7024 and for water at the same pressures is negligible.

- By increasing the pressure, the breakup length of spray decreases and jet breakup to droplets occurs at a shorter distance from the tip of nozzle.

\subsection{Experiment Error Analysis}

The error analysis of this experiment is based on a mathematical formula. This type of analysis can be performed for the flow rate measurement, which is as follows:

$Q=\frac{V}{t} \rightarrow \log Q=\log V-\log t$

where, $Q, V$, and $t$ are volumetric flow rate, fluid volume, and time respectively. To measure the percentage of experimental error, we must differentiate the above equation and consider its absolute values:

$$
\frac{\mathrm{d} Q}{Q}=\frac{\mathrm{d} V}{V}+\frac{\mathrm{d} t}{t}
$$

where $\mathrm{d} V$ and $\mathrm{d} t$ is the accuracy of measuring values or the minimum value that can be measured with volume and timing measuring tools.

Table 2 Experiment measurable parameters' error

\begin{tabular}{|c|c|c|}
\hline \multicolumn{2}{|c|}{ Table 2 Experiment measurable parameters' error } \\
\hline $\begin{array}{c}\text { Average level of } \\
\text { measurement for each } \\
\text { step }\end{array}$ & $\begin{array}{c}\text { Measurement } \\
\text { accuracy }\end{array}$ \\
\hline Graded test container & $50.4 \mathrm{cc}$ & $2 \mathrm{cc}$ \\
\hline Human reaction & $13.858 \mathrm{~s}$ & $0.5 \mathrm{~s}$ \\
\hline
\end{tabular}

Thus based on the data given in Tab. 2, flow rate error is calculated as below:

$$
\frac{\mathrm{d} V}{V}+\frac{\mathrm{d} t}{t}=\frac{2}{50.4}+\frac{0.5}{13.858} \cong 7.5 \%
$$

Thus we have around $7.5 \%$ error in flow rate measurement. It means if the flow rate is reported $100 \mathrm{cc} / \mathrm{s}$, the real value equals to $100 \pm 7.5 \mathrm{cc} / \mathrm{s}$.

\section{GOVERNING EQUATIONS}

The governing equations of the continuous phase (air) are the well-known Navier-Stoks equations. The flow of air in the control volume out of the injector is simulated based on the equations as follows [22]:

$\frac{\partial \rho}{\partial t}+\nabla \cdot(\rho u)=\rho^{\circ}$

Eq. (4) is the continuity equation in which $t, \rho, u$ and $\rho^{\circ}$ are time, density, velocity and the vaporized mass of the drops, respectively.

The second equation is the conservation of momentum, Eq. (5), where $g, \mu$ are gravity and dynamic viscousity coefficients, $p, f^{\circ}$ are spraying parameters related to pressure and spraying momentum, respectively.

$\rho \frac{\mathrm{d} u}{\mathrm{~d} t}=\rho g-\nabla p+\mu \nabla^{2} u+f^{\circ}$

The third one is the energy conservation equation. In general, this equation is like Eq. (6). In this equation $C p, \lambda$, $T$, and $q^{\circ}$ are specific heat in constant pressure, thermal conduction coefficient, temperature and released heat of drops.

$\rho C p\left(\frac{\partial T}{\partial t}+u . \nabla T\right)=\nabla \cdot(\lambda \nabla T)+q^{\circ}$

Particle tracing (discrete phase) in the control volume in interaction with the continuous phase, follows Eq. (7). In this equation different terms can be included such as: 
drag force, gravity force and other forces including: pressure gradient and forces resulting from brownian motion of particles. This depends on the type of the question and the significance of these factors.

$$
\frac{\mathrm{d} u_{\mathrm{p}}}{\mathrm{d} t}=F_{\mathrm{D}}\left(u-u_{i}\right)+g \frac{\rho_{\mathrm{p}}-\rho}{\rho_{\mathrm{p}}}+F
$$

where: $u_{\mathrm{p}}$ the velocity of particles(discrete phase), $\mathrm{u}$ air velocity (continuous phase), $F_{\mathrm{D}}$ drag force in the particle mass unit, $\rho_{\mathrm{p}}$ particle density, $\rho$ liquid density, and $F$ is external forces.

\section{MODELING AND NETWORKING}

In order to implement numerical research and modeling process, first we should design the geometry of the problem based on the schematic of the injector (Fig. 5).

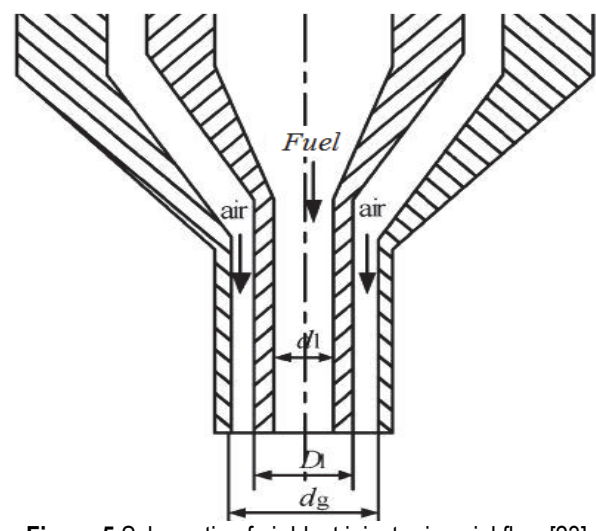

Figure 5 Schematic of air blast injector in axial flow [23]
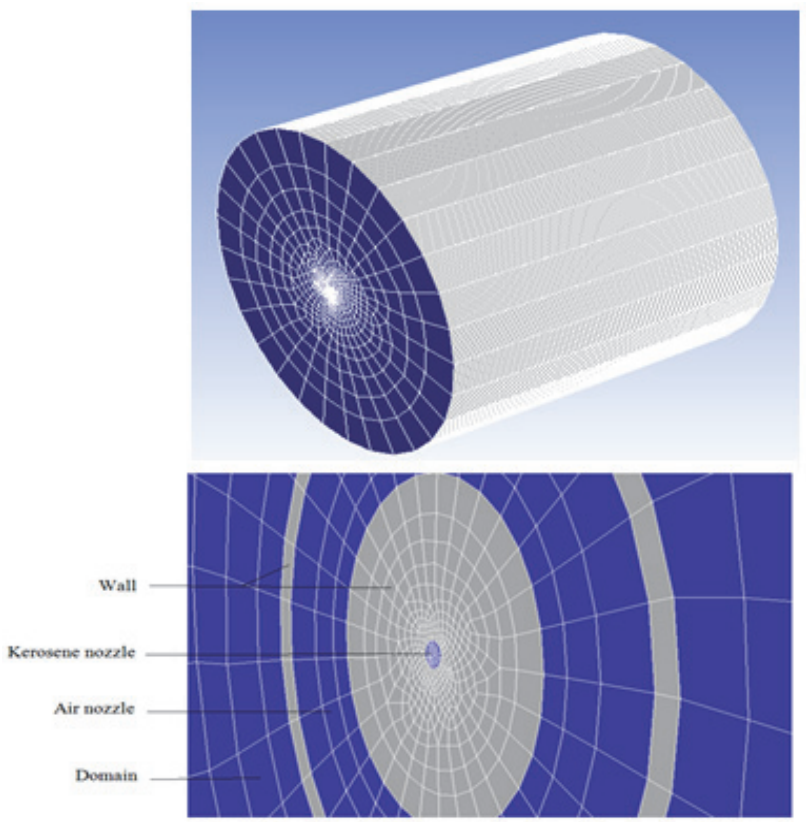

Figure 6 The grids of fuel and air duct outlets with the solution domain

The dimensions of the fuel nozzle and the air duct in the atomizer are: $d_{1}=0.25 \mathrm{~mm}, D_{1}=3.25 \mathrm{~mm}, d_{\mathrm{g}}=5.8 \mathrm{~mm}$ (Fig. 5). After modeling, we should mesh it. In the meshing process, the computational cost should be taken into account. On the other hand, sensitive and important points should necessairily be covered. With regard to Fig. 5 a cylindrical shape with $75 \mathrm{~mm}$ diameter and $150 \mathrm{~mm}$ height is considered as solution domain. This will cover the spraying area easily. Fig. 6 shows the fuel nozzle outlet and its meshing. Grid independency was studied and the results are shown in Fig. 7. Based on this figure, the number of computational grid cells is considered about 250000 cells. In this simulation, the mass flow rate of kerosene and air was $0.939 \mathrm{gr} / \mathrm{s}$ and $17.91 \mathrm{gr} / \mathrm{s}$ respectively and the time step size was $0.01 \mathrm{~s}$.

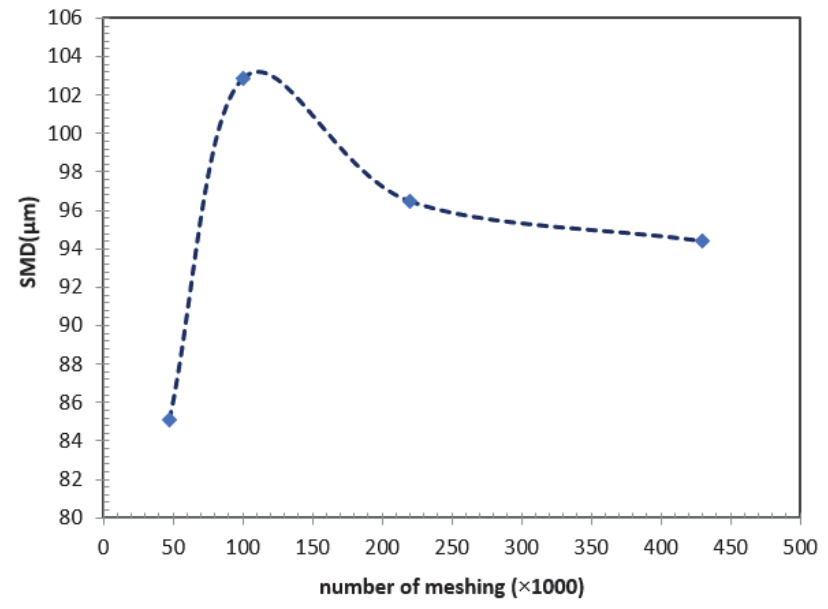

Figure 7 Diagram of grid independency study

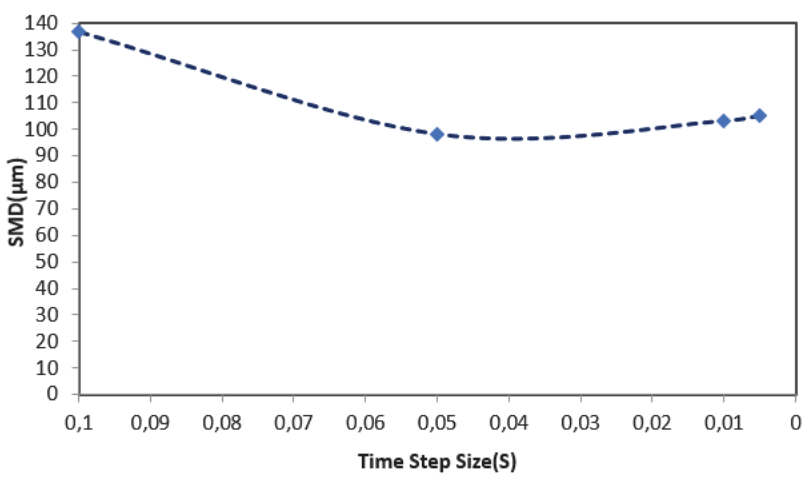

Figure 8 Graph of independence of results from time step

\section{NUMERICAL SOLUTION METHOD}

In order to simulate the problem, the real information of the ALF502 is used, [21]. This information is shown in Tab. 3. In order to simulate the two phase flow the discrete phase model is used. The boundary condition for all particles close to boundaries except exit boundaries is reflection criteria and for exit boundaries it is escaping criteria. The initial break shows the condition of drops that exit the nozzle. These drops are the result of breaking for core of high density liquid. The internal effects of the nozzle (like cavitation) and transfer from internal nozzle volume to a high density spray will usually result in this type of the break, [24]. The fuel used in the simulations is kerosine liquid (The specifications of kerosine in the fluent software database, are as follows: density $=780 \mathrm{~kg} / \mathrm{m}^{3}$, viscosity coefficient $=0.0024 \mathrm{~kg} / \mathrm{ms}$, specific heat capacity $=2090 \mathrm{~J} / \mathrm{kgK}$ ). It is worth mentioning that commercial fuels in aviational industry are known with commercial names such as: JP5, JP4 and so on. They are all part of the kerosene family. Choosing a proper solving method, 
boundary conditions and transient or steady solution are amongst the choices that will result in sufficient convergence and speed. Here the air flow is considered as steady state and spraying is considered as transient flow; since the spraying condition is transient and steady state solution for it might result in a non-physical answers. In order to investigate the time step, the average drop diameter is analyzed based on different time steps. The results can be seen in Fig. 8. The kerosene flow rate and air flow rate in this study are considered $0.939 \mathrm{gr} / \mathrm{s}$ and 17.91 $\mathrm{gr} / \mathrm{s}$, respectively and the number of calculation cells is 220000. Based on the results the time step is chosen $0.05 \mathrm{~s}$.

\section{RESULTS AND DISCUSSION}

As mentioned earlier, previous studies, including [3], indicate that ambient pressure has little effect on the average droplet diameter, but reduces the angle of the injection cone. On the other hand, according to previous studies, such as [11] if we consider the results solely on the basis of variation in air-to-fuel ratio, it is expected that by increasing air-to-fuel ratio, the average droplet diameter decreases and the cone angle increases. However, in the real situation, pressure and discharge rate change simultaneously and analyzing the results based solely on one parameter could not be logical; so it would be more logical to analyze the results based on a parameter that combines all the important effectve parameters. The purpose of this study was to address this issue and to do this a dimensionless number has been introduced and defined. In fact, this dimensionless number, called $K$, reflects the combined effects of fuel and air discharge parameters and ambient pressure and it is defined as Eq. (8):

$$
K=\left[\left(\dot{m}_{\text {kerosene }} / \dot{m}_{\text {air }}\right) \cdot\left(P_{\text {atm }} / P_{\text {cc }}\right)\right]
$$

where: $\dot{m}_{\text {kerosene }}$ and $\dot{m}_{\text {air }}$ duct are shown in Fig. $5 . P_{\text {cc }}$ is the downstream pressure (combustion chamber pressure which the fuel is injected into).

Eq. (8) is a general relation for different conditions, for example, when spraying is done at standard atmospheric pressure, then the second part of Eq. (8) will be equal to 1. Fig. 9 shows the spray simulation for 3 modes of the dimensionless number $K$. As it can be seen by increasing the dimensionless number $K$, the spray cone angle and the distance between droplets decreases.

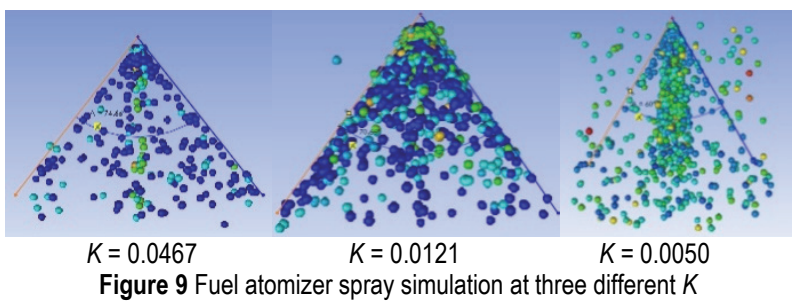

Tab. 3 summarizes the simulation results. In this table, the fuel mass flow rate and combustion chamber pressure are according to the actual operating condition of ALF502 engine data [21], and the air mass flow rate is calculated according to the combustion chamber pressure and the holes on the fuel nozzle body using the Bernoulli's equation.

Table 3 Summary of fuel atomizer simulation results

\begin{tabular}{|c|c|c|c|c|c|c|c|}
\hline Speed / rpm & $P_{\mathrm{cc}} / \mathrm{bar}$ & $\dot{m}_{\text {air }} / \mathrm{gr} / \mathrm{s}$ & $\dot{m}_{\text {kerosene }} / \mathrm{gr} / \mathrm{s}$ & $K=\left[\left(\dot{m}_{\text {kerosene }} / \dot{m}_{\text {air }}\right) \cdot\left(P_{\text {atm }} / P_{\mathrm{cc}}\right)\right]$ & $S M D_{\text {primary }} / \mu \mathrm{m}$ & $S M D_{\text {secondary }} / \mu \mathrm{m}$ & Spray cone angle / deg \\
\hline 9600 & 1.12 & 17.91 & 0.939 & 0.0467 & 102.7 & 6.18 & 60 \\
\hline 11400 & 1.47 & 20.52 & 1.59 & 0.0526 & 86.8 & 5.15 & 64.97 \\
\hline 12700 & 1.57 & 22.39 & 1.88 & 0.0479 & 60.2 & 4.51 & 66.3 \\
\hline 16200 & 4.06 & 34.10 & 3 & 0.0216 & 32.9 & 2 & 67.82 \\
\hline 17700 & 6.03 & 42.72 & 3.3 & 0.0121 & 12.1 & 0.74 & 70.66 \\
\hline 18700 & 10.08 & 53.74 & 3.7 & 0.0068 & 10.2 & 0.62 & 72.35 \\
\hline 19520 & 13.13 & 61.08 & 4.03 & 0.0050 & 7.8 & 0.47 & 74.66 \\
\hline
\end{tabular}

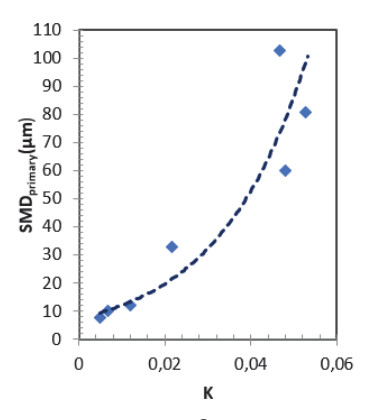

a
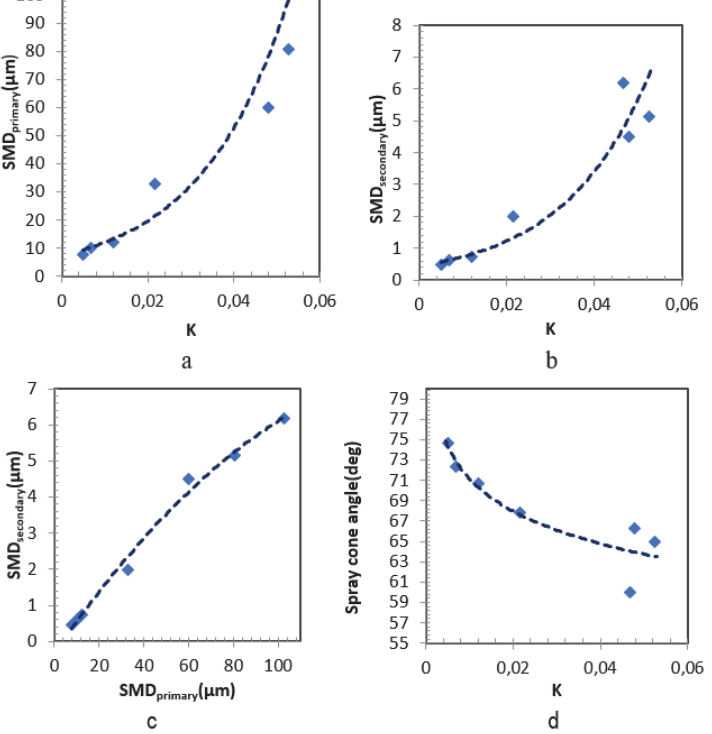

Figure 10 Average diameter of droplets in primary and secondary breakup and spray cone angle according to dimensionless number $K$
Fig. 10a shows the mean diameter variations of the droplets caused by the initial failure according to the dimensionless number $K$. As can be seen from this graph, when the dimensionless number $K$ increases, the diameter of the droplets due to initial failure increases, which is initially associated with a slower slope and then a steeper slope. Fig. 10b shows the mean diameter variations of droplets caused by the secondary failure in terms of the dimensionless number $K$. Compatible with Fig.10a, as the dimensionless number $K$ increases, the diameter of the droplets resulting from the secondary fracture increases. Fig. 10c shows the diagram of changes in droplets diameter due to secondary failure in terms of the average diameter of droplets caused by the primary failure which shows an almost linear relationship between them. Fig. 10d shows the spray cone angle variations in terms of the dimensionless number $K$. As can be seen from this diagram, by increasing the dimensionless number $K$, the spray cone angle decreases, initially with a steeper slope and then a slower slope. In summary, the results of the 
simulation of this atomizer based on the dimensionless $K$ number can be understood as follows:

1. With the increment of the dimensionless number $K$, the mean diameter of the droplets due to the primary and secondary spray failure increases, which is slightly higher in the primary failure process than the secondary failure. According to the curves of Fig. 10 and with regard to the maximum obtainable regression coefficient $\left(R^{2}\right)$, the following equations could be derived to estimate the mean diameter of droplets caused by primary and secondary failures:

$$
\begin{array}{lc}
S M D_{\text {primary }}(\mu \mathrm{m})=7.4088 \mathrm{e}^{49.115 K} & \left(R^{2}=0.9335\right) \\
S M D_{\text {secondary }}(\mu \mathrm{m})=0.4407 \mathrm{e}^{51.173 K} & \left(R^{2}=0.952\right) \\
& \\
S M D_{\text {secondary }}(\mu \mathrm{m})=0.0003\left(S M D_{\text {primary }}\right)^{2}+ & \\
0.0892\left(S M D_{\text {primary }}\right)-0.3029 & \left(R^{2}=0.9921\right)
\end{array}
$$

2. By increasing the dimensionless number $K$, the spray cone angle decreases initially with a steeper slope. Considering the curve in Fig. 10d and the maximum amount obtainable for the regression coefficient $\left(R^{2}\right)$, the following relation is given to estimate the spray cone angle:

Spray cone angle $(\mathrm{deg})=-4.596 \ln (K)+49.995$

$\left(R^{2}=0.8307\right)$

\section{VALIDATION}

In all reaseraches the most important part is validating the numerical results by the experimental ones. The comparison between numerical solution and experimental data is shown in Fig. 11, Fig. 12 and also Tab. 4.

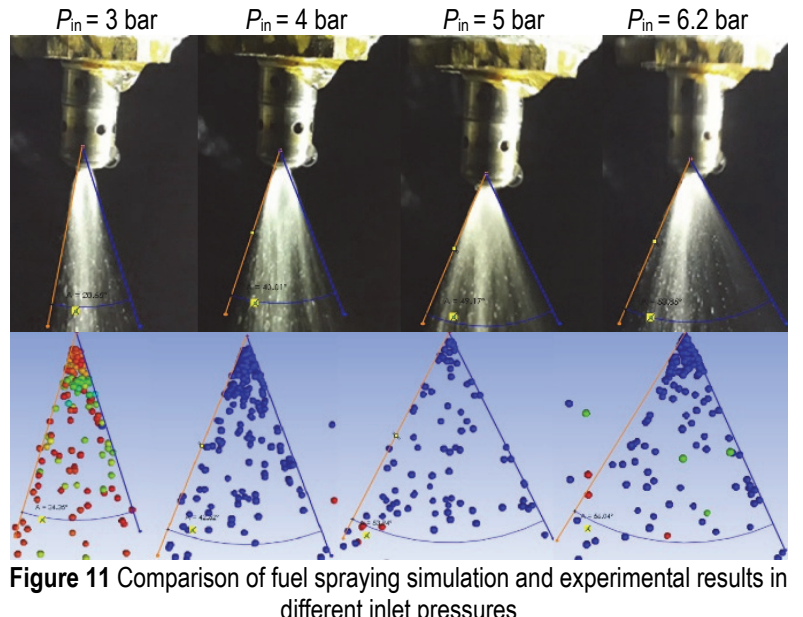

In average the deviation of numerical results from the experimental results is $9.98 \%$, which shows an acceptable agreement.

Table 4 Spray conel angle resulting from numerical simulation and experiment at different pressures

\begin{tabular}{|c|c|c|c|c|}
\hline $\begin{array}{c}p / \\
\text { bar }\end{array}$ & $\begin{array}{c}\text { Spray cone angle } \\
\text { in experimental test } \\
/ \text { deg }\end{array}$ & $\begin{array}{c}\text { Spray cone angle } \\
\text { in the numerical } \\
\text { simulation / deg }\end{array}$ & Error & $\begin{array}{c}\text { Average } \\
\text { Error }\end{array}$ \\
\hline 3 & 28.65 & 34.35 & $19.89 \%$ & \\
\hline 4 & 40.01 & 42.52 & $6.27 \%$ & \\
\hline 5 & 49.17 & 53.94 & $9.70 \%$ & $9.98 \%$ \\
\hline 6.2 & 53.85 & 50.04 & $4.06 \%$ & \\
\hline
\end{tabular}

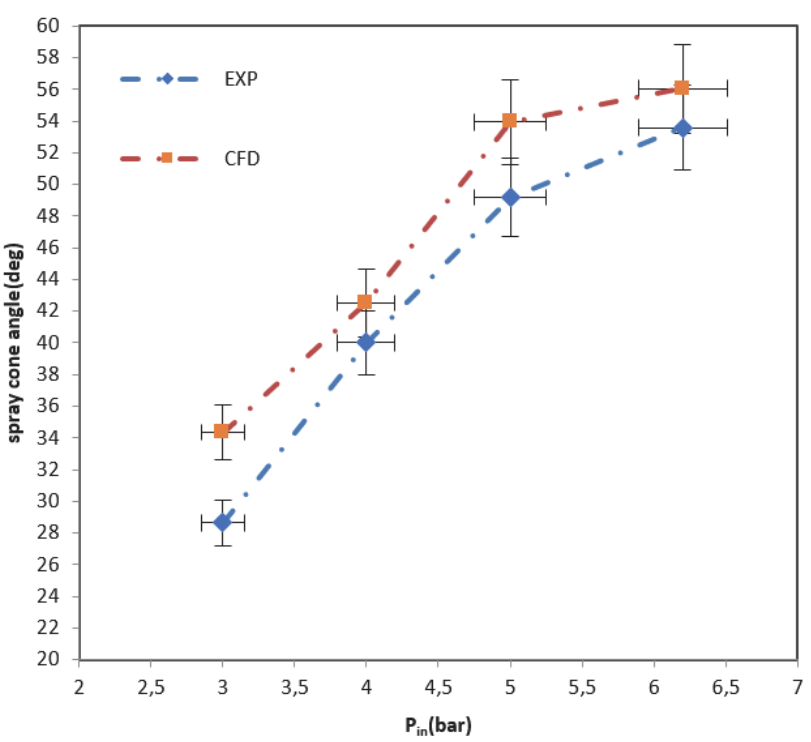

Figure 12 The comparison of fuel spray cone angle resulting from simulation with experimental one at different inlet pressures

\section{CONCLUSION}

In this research air blast atomizer of a jet engine is studied in the real working situation. For this reason, the real data of ALF502 was used. Numerical and experimental methods were applied. Since in the real situation none of fuel flow rate, air flow rate and the ambient pressure is constant, it is better to consider the effects of all parameters simultaneously. Thus, in this research to estimate air blast atomizer spray, nondimensional $K$ number is defined. The main parameters of the fluid including fuel and air flow rates, and spraying ambient pressure are related to each other by $K$ parameter.

The analysis of results based on $K$ number is as below:

1) By increasing non-dimensional $K$ number, the average drops diameter produced by initial and secondary breakup increases. This increment is higher in the first breakup than the second one.

2) By increasing non-dimensional $K$ number, the spray cone angle decreases, this decrement initially happens at a higher slope.

The result of this research can be used in the design of fuel injection systems in jet engines, in which fuel injection quality is an important factor in the engine efficiency.

\section{REFERENCES}

[1] Ommi, F., Hosseinalipour, S. M., Kargar, A., Eng, M., Movahed, E., \& Nekofar, K. (2010). Experimental Investigation of Characteristics of a Double-Base Swirl Injector In a Liquid Rocket Propellant Engine. Thermal Science, 14(2), 479-491. https://doi.org/10.2298/TSCl10024790

[2] Rizkalla, A. A. \& Lefebvre, A. H. (1975). The influence of air and liquid properties on airblast atomization. Journal of Fluids Engineering, 97(3), 316-320. https://doi.org/10.1115/1.3447309

[3] Zheng, Q. P., Jasuja, A. K., \& Lefebvre, A. H. (1997). Structure of airblast sprays under high ambient pressure conditions. Journal of Engineering for Gas Turbines and Power, 119(3), 512-518. https://doi.org/10.1115/1.2817014 
[4] Fan, W. J., Xiao, Q., Yang, Y., \& Yang, M. L. (2002). Study on New Airblast Atomizers and the Spray Characteristic. Journal of Engineering Thermophysics, 23(3), 391-393.

[5] Levy, Y., Sherbaum, V., Levin, D., \& Ovcharenko, V. (2005, January). Airblast Swirl Atomizer for Small Jet Engines. ASME Turbo Expo 2005: Power for Land, Sea, and Air, 905911. https://doi.org/10.1115/GT2005-68314

[6] Koch, R., Bauer, H. J., \& Hehle, M. (2006, January). Performance of prefilming airblast atomizers in unsteady flow conditions. ASME Turbo Expo 2006: Power for Land, Sea, and Air, 337-345.

[7] Zhang, S. R. \& Yin, H. C. (2007). Spray numerical simulation of air blast fuel-oil atomizer. Energy Technology, 28, 14-16.

[8] Batarseh, F. Z., Gnirß, M., Roisman, I. V., \& Tropea, C. (2009). Fluctuations of a spray generated by an airblast atomizer. Experiments. https://doi.org/10.1007/s00348-009-0612-y

[9] Grech, N., Mehdi, A., Zachos, P. K., Pachidis, V., \& Singh, R. (2012). Effect of combustor geometry on performance of airblast atomizer under sub-atmospheric conditions. Engineering Applications of Computational Fluid Mechanics, 6(2), 203-213. https://doi.org/10.1080/19942060.2012.11015415

[10] Gepperth, S., Koch, R., \& Bauer, H. J. (2013, June). Analysis and comparison of primary droplet characteristics in the near field of a prefilming airblast atomizer. ASME Turbo Expo 2013: Turbine Technical Conference and Exposition. American Society of Mechanical Engineers Digital Collection. https://doi.org/10.1115/GT2013-94033

[11] Chong, C. T. \& Hochgreb, S. (2014). Spray characteristics of an internal-mix airblast atomizer. Applied Mechanics and Materials, 629, 125-130. https://doi.org/10.4028/www.scientific.net/AMM.629.125

[12] Chaussonnet, G., Vermorel, O., Riber, E., \& Cuenot, B. (2016). A new phenomenological model to predict drop size distribution in Large-Eddy Simulations of airblast atomizers. International Journal of Multiphase Flow, 80, 29-42. https://doi.org/10.1016/j.jimultiphaseflow.2015.10.014

[13] Shafaee, M. \& Mahmoudzadeh, S. (2017). Numerical investigation of spray characteristics of an air-blast atomizer with dynamic mesh. Aerospace Science and Technology, 70, 351-358. https://doi.org/10.1016/j.ast.2017.08.024

[14] Roudini, M. \& Wozniak, G. (2018). Experimental investigation of spray characteristics of pre-filming air-blast atomizers. Journal of Applied Fluid Mechanics, 11, 14551469. https://doi.org/10.29252/jafm.11.06.28115

[15] Khani Aminjan, K., Heidari, M., \& Rahmanivahid, P. (2020). Study of spiral path angle in pressure-swirl atomizer with spiral path. Archive of Applied Mechanics. https://doi.org/10.1007/s00419-020-01803-2

[16] Khani Aminjan, K., Kundu, B., \& Ganji, D. D. (2020). Study of Pressure-Swirl Atomizer with Tangential Input at Design Point and Outside of Design Point. Physics of Fluids, 32(12). https://doi.org/10.1063/5.0032174

[17] Jamali, M., Rostamijavanani, A., Nouri, N. M., \& Navidbakhsh, M. (2020). An experimental study of cavity and Worthington jet formations caused by a falling sphere into an oil film on water. Applied Ocean Research, 102, 102319. https://doi.org/10.1016/j.apor.2020.102319

[18] Zhou, G., Xu, M., Qiu, H., Nie, W., Cheng, W., \& Chen, C. (2017). Experimental investigation about the influence of airflow on droplet sizes of mechanical nozzles for coal mining face. Tehnički vjesnik, 24(6), 1713-1721. https://doi.org/10.17559/TV-20151002110105

[19] Mrzljak, V. \& Žarković, B. (2019). Numerical Analysis of the Fuel Spray Packages Penetration and Gas Inflow from Quasi-Dimensional Di Diesel Engine Numerical Model. Zbornik Veleučilišta u Rijeci, 7(1), 335-357. https://doi.org/10.31784/zvr.7.1.11
[20] Seyedin, S.H., Ahmadi, M., \& Seyedin, S. V. (2019). Design and Construction of the Pressure Swirl Nozzle and Experimental Investigation of Spray Characteristics. Tehnički glasnik, 13(3), 204-212. https://doi.org/10.31803/tg-20180908135420

[21] Honeywell, Engine Manual alf502r, Temporary Revision No. $72-1009$ (to holders of turbofan aircraft engine manual report no. 286.1, revision 27, dated 27 aug 2004. This tr is also applicable to the cd-rom alf502r_l and the cd-rom alf502r h).

[22] Kärrholm, F. P. (2008). Numerical Modelling of Diesel Spray Injection, Turbulence Interaction and Combustion. Gothenburg, Sweden: Chalmers University of Technology.

[23] Jiang, D. J., Liu, H. F., Li, W. F., Xu, J. L., Wang, F. C., \& Gong, X. (2012). Modeling Atomization of a Round Water Jet by a High-Speed Annular Air Jet Based on The SelfSimilarity of Droplet Breakup. Chemical Engineering Research and Design, 90(2), 185-192. https://doi.org/10.1016/j.cherd.2011.07.006

[24] Payri, F., Bermúdez, V., Payri, R., \& Salvador, F. J. (2004). The Influence of Cavitation on the Internal Flow and the Spray Characteristics in Diesel Injection Nozzles. Fuel, 83(4-5), 419-431. https://doi.org/10.1016/j.fuel.2003.09.010

\section{Contact information}

Mohammad Mehdi DOUSTDAR, Professor

Department of Engineering,

Imam Hossein University,

Tehran, Iran

E-mail:mdostdar@ihu.ac.ir

Kiumars KHANI AMINJAN, Research Scholar

(Corresponding author)

Faculty of Aerospace,

Malek Ashtar University of Technology,

Tehran, Iran

E-mail: kiumars.khani67@gmail.com

Houman ALIPOUR

Caspian Faculty of Engineering,

College of Engineering, University of Tehran,

Tehran, Iran

E-mail: Hoomanalipoor@ut.ac.ir

\section{Maryam ALIAKBAR}

Department of Mechanical and Aerospace Engineering, Science and Research Branch, Islamic Azad University, Tehran, Iran

E-mail: maryamaliakbari2008@yahoo.com 